\title{
ENA STUDY OF POSSIBLE IMPROVEMENT IN FORMULATION DESIGN PRACTICES FOR OPTIMIZED PERFORMANCE OF Zn AND AI PIGMENTED EPOXY COATINGS
}

\author{
${ }^{1}$ Boleslav EREMIÁŠ, ${ }^{1}$ Libor TUREK, ${ }^{1}$ Lubomír MINDOŠ, ${ }^{2}$ Libuše HOCHMANNOVÁ \\ 1SVUOM Ltd., Prague, Czech Republic, EU, eremias@svuom.cz \\ ${ }^{2}$ SYNPO Inc., Pardubice, Czech Republic, EU, libuse.hochmannova@synpo.cz
}

https://doi.org/10.37904/metal.2019.876

\begin{abstract}
The effect of the ratio of the pigment volume concentration (PVC) to the critical pigment concentration (CPVC) belongs to well-known formulation design practices for optimized performance of pigmented organic coatings. The influence of this ratio in $\mathrm{Zn}$ an Al pigmented epoxy coatings on delamination kinetics of underlying steel has been investigated by electrochemical noise analysis (ENA) during $168 \mathrm{hrs}$ immersion tests in $0.05 \mathrm{M} \mathrm{NaCl}$. Two different $\mathrm{Zn}$ and $\mathrm{Al}$ pigmented epoxy coatings were prepared with different PVC/CPVC values but with the same vol. \% $\mathrm{Zn}: \mathrm{Al}$ ratio as well as with the same binder and hardener types applied. ENA was used to provide information about possible effect of PVC/CPVC values on delaminated corroding area time development in tested coating/steel systems. It has been concluded that in these systems it is recommended the use of certain low PVC/CVPC value in order to obtain high resistance to possible coating delamination from the metallic surface.
\end{abstract}

Keywords: Electrochemical noise, pigmented epoxy coatings, delamination

\section{INTRODUCTION}

As recent findings show [1] the composition as well as the structure of $\mathrm{Zn}$ and Al pigmented epoxy coatings should be considered as possible factors affecting delamination kinetics at the metal surface beneath the coating. At the same time correlation found between electrochemical noise (EN) measurements of delamination and results of physico-mechanical tests suggests that pigment inhomogeneity and localized voids formation can be one of possible reasons for increased tendency to delamination observed for some coating systems. In this case the question arises if by proper manipulations of the parameter whose variation have a significant effect on voids formation possible improvement in formulation of newly designed coating systems can be obtained. As the ratio of the pigment volume concentration (PVC) to the critical pigment concentration (CPVC), denoted by $\Lambda$ is in relation to voids formation [2,3], an attempt was made to answer this question. For this purpose two different $\mathrm{Zn}$ and $\mathrm{Al}$ pigmented epoxy coating systems with different $\Lambda$ were applied on steel substrate specimens. Electrochemical noise analyses (ENA) was then used to provide information about possible delaminated corroding area time development for both tested systems during $168 \mathrm{hrs}$ immersion tests in $0.05 \mathrm{M} \mathrm{NaCl}$. Apart of EN measurements more advanced microscopic methods were used for metallographic analysis of tested coatings after immersion tests. EDX mapping and structure (SEM-SE image) of crosssections were chosen for this purpose. The main aim of this study was to improve formulation design practices for optimized performance of $\mathrm{Zn}$ and Al pigmented epoxy coatings.

\section{EXPERIMENTAL}

\subsection{Materials}

Two types of pigmented epoxy coatings were prepared using Zn dust 4P16 and Al paste Aluminium Stapa $2 \mathrm{NL}$ with the same binder and hardener combination but with different volumes of all pigments and polymer matrix components (Tables 1 - 4). 
In order to avoid the particles settlement and for better dispersion ion-exchangeable inorganic pigment Syloid 244 based on synthetic amorphous silica was used in both types of tested coatings. Concerning preparation both types of coatings were prepared by mixing of Zn dust 4P16, Al paste Aluminium Stapa 2NL and Syloid 244. For dissolution of this mixture in given type of binder dissolver Netzsch and cooling water conditions were used.

Table 1 Characteristics of tested ZRP with Al additions

\begin{tabular}{|c|c|c|c|c|c|}
\hline sample & $\begin{array}{c}\text { OPVC } \\
\text { (vol\%) }\end{array}$ & $\begin{array}{c}\text { Zn:Al ratio } \\
\text { (vol\%) }\end{array}$ & Filler & Binder & Hardener \\
\hline AKAI 113 & 45 & $88: 12$ & Alum.Stapa 2NL & Epikote 1001 & Epicure 3115 \\
\hline AKAI 115 & 55 & $88: 12$ & Alum.Stapa 2NL & Epikote 1001 & Epicure 3115 \\
\hline
\end{tabular}

Table 2 Characteristics of AKAl 113 in relation to volumes of components having effect on $\wedge$ value

\begin{tabular}{|c|c|c|}
\hline component & $\begin{array}{c}\text { V different pigment components } \\
\left(\mathbf{c m}^{\mathbf{3}}\right)\end{array}$ & $\begin{array}{c}\text { V different polymer matrix } \\
\text { components }\left(\mathbf{c m}^{\mathbf{3}}\right)\end{array}$ \\
\hline Zn4P16 & 38.25 & - \\
Alum. Stapa 2NL & 5.22 & - \\
Syloid 244 & 1.53 & 39.30 \\
Epikote 1001-X75 & - & 15.70 \\
Epicure 3115-X75 & - & - \\
\hline
\end{tabular}

Table 3 Characteristics of AKAl 115 in relation to volumes of components having effect on $\wedge$ value

\begin{tabular}{|c|c|c|}
\hline component & $\begin{array}{c}\text { V different pigment components } \\
\left(\mathbf{c m}^{\mathbf{3}}\right)\end{array}$ & $\begin{array}{c}\text { V different polymer matrix } \\
\text { components }\left(\mathbf{c m}^{3}\right)\end{array}$ \\
\hline Zn4P16 & 46.75 & - \\
Alum. Stapa 2NL & 6.38 & - \\
Syloid 244 & 1.87 & 32.16 \\
Epikote 1001-X75 & - & 12.84 \\
Epicure 3115-X75 & - & - \\
\hline
\end{tabular}

Table 4 Characteristics of tested coating systems in relation to $\Lambda$ values (calculated for $\mathrm{Zn}$ particles in tested coating systems)

\begin{tabular}{|c|c|c|}
\hline sample & PVC & $\Lambda$ \\
\hline AKAl 113 & 0.4102 & 0.6133 \\
\hline AKAl 115 & 0.5095 & 0.7618 \\
\hline
\end{tabular}

Both tested coatings were applied by spreader bar to steel $\mathrm{C} 4 \mathrm{Q}$ panels previously polished and degreased.

\subsection{Methods}

Immersion tests using ENA for tested coatings on steel substrate specimens were performed with use of the same experimental set-up as described earlier [4]. The potential and current noise (ENP and ENC) values (for given data set measured for given immersion time) were collected for measurement periods of $600 \mathrm{~s}$ with sampling rate of $20 \mathrm{~Hz}$ (12 000 points for period) using GAMRY ESA 410 software. Similarity of MEM Noise Impedance Spectrum characteristics with simulated electrochemical impedance spectrum for which impedance analog for coated steel is accepted [5] was used to provide information about disbonded region of 
the coating/steel interface in relation to double-layer capacitance $C_{d}$ values as well as delaminated corroding area $A_{d}$ values changing with immersion time t. For this purpose $A_{d}(t)$ can be estimated from $C_{d}$ values measured at given time $t(\mu \mathrm{F})$ by means of empirical equation $A_{d}=C_{d}(t) / 20$ if 20 is the typical value of the bare steel double-layer capacitance adopted to estimate the underlying metallic active surface $\left(\mu \mathrm{F} . \mathrm{cm}^{-2}\right)[6]$.

\section{RESULTS AND DISCUSSIONS}

Nine measurements were performed on type specimen AKAl113 as well as on type specimen AKAl115 during uninterrupted immersion tests performed on steel panels coated by tested coating systems. Table 5 lists the parameters obtained by mentioned approach to analysis of 9 sets of ENA data for AKAl113 and AKAl115. These parameters included instantaneous $C_{d}$ and $A_{d}$ values estimated for given immersion time. Due to very dynamic changes of cathodic nature of steel surface with immersion time, the average delaminating area $\left(A_{d, a v}\right)$ time development in $168 \mathrm{hrs}$ exposure of tested coating systems to $0.05 \mathrm{M} \mathrm{NaCl}$ was chosen for evaluation of delamination kinetics of underlying steel. $A_{d, a v}$ development with immersion time in immersion tests using ENA and performed on tested steel/paint systems can be seen in Figure 1.

Table 5 Instantaneous $C_{d}$ and $A_{d}$ values for AKAl113 and AKAl115 after different immersion time

\begin{tabular}{|c|c|c|c|c|}
\hline \multirow{2}{*}{$\begin{array}{c}\text { Immersion time } t \\
\text { (hrs) }\end{array}$} & \multicolumn{2}{|c|}{ AKAl113 } & \multicolumn{2}{|c|}{ AKAl115 } \\
\hline & $C_{d}(F)$ & $A_{d}\left(\mathrm{~cm}^{2}\right)$ & $C_{d}(F)$ & $A_{d}\left(\mathrm{~cm}^{2}\right)$ \\
\hline 24 & $5.91 \cdot 10^{-10}$ & $2.96 \cdot 10^{-5}$ & $6.52 \cdot 10^{-9}$ & $3.26 \cdot 10^{-4}$ \\
\hline 29 & $8.95 \cdot 10^{-10}$ & $4.48 \cdot 10^{-5}$ & $5.54 \cdot 10^{-9}$ & $2.77 \cdot 10^{-4}$ \\
\hline 48 & $6.49 \cdot 10^{-10}$ & $3.25 \cdot 10^{-5}$ & $1.41 \cdot 10^{-8}$ & $1.41 \cdot 10^{-4}$ \\
\hline 53 & $1.63 \cdot 10^{-8}$ & $8.16 \cdot 10^{-4}$ & $7.54 \cdot 10^{-9}$ & $3.77 \cdot 10^{-4}$ \\
\hline 72 & $5.40 \cdot 10^{-10}$ & $2.70 \cdot 10^{-5}$ & $3.25 \cdot 10^{-8}$ & $1.62 \cdot 10^{-3}$ \\
\hline 77 & $1.06 \cdot 10^{-8}$ & $5.31 \cdot 10^{-4}$ & $2.67 \cdot 10^{-6}$ & $1.34 \cdot 10^{-1}$ \\
\hline 96 & $5.48 \cdot 10^{-9}$ & $2.74 \cdot 10^{-4}$ & $3.27 \cdot 10^{-6}$ & $1.64 \cdot 10^{-1}$ \\
\hline 101 & $9.05 \cdot 10^{-9}$ & $4.52 \cdot 10^{-4}$ & $1.11 \cdot 10^{-7}$ & $5.53 \cdot 10^{-3}$ \\
\hline 168 & $2.27 \cdot 10^{-9}$ & $1.14 \cdot 10^{-4}$ & $8.93 \cdot 10^{-8}$ & $4.46 \cdot 10^{-3}$ \\
\hline
\end{tabular}

From Table 5 as well as from Figure 1 can be seen the $C_{d}$ value can be used as a measure of the area over which coating had been disbonded. It should be noticed this parameter can be well measured only when some minimum degree of deterioration of coating is reached. For AKAl113 it was found this value can be very low $\left(A_{d, a v}=3.10^{-5} \mathrm{~cm}^{2}\right.$ after $24 \mathrm{hrs}$ of exposure to $0.05 \mathrm{M} \mathrm{NaCl}$ ) when comparing with AKAl115 (see Table 5). This finding is not surprising because value of $\Lambda$ for AKAl113 is so low it can be considered to be even lower than the random densest packing value for mono-sized spheres which is 0.64 [2,7]. In spite of some modification of this value for a distribution [3] of pigment sizes, with a possible absorbed layer of polymer [8] (considered as may be larger or smaller than 0.64 ) for reasons of simplicity value 0.64 can be used as boundary condition for possible voids formation in pigmented organic coatings. If this suggestion is accepted, the structure of AKAl113 is in the state on no voids formation so that only $\mathrm{O}_{2}$ permeability of this coating can be considered as affecting kinetics of delamination by possible formation of $\mathrm{NaOH}$ in disbonded region. In fact water and $\mathrm{O}_{2}$ permeability can be supposed to be also decreased but only just to degree allowing the rate of dissolution of $\mathrm{Zn}$ and Al particles was able to modify friendly the interfacial environment beneath the coating.

In comparison with AKAl113 coating system AKAl115 seems not to be able to exhibit the same effect. In opposite to AKAl113 some localized voids formation with accumulation of $\mathrm{Cl}^{-}$ions in it was observed for AKAl115 when metallographic analysis has been performed after the test (see Figures 2 and 3 ). 


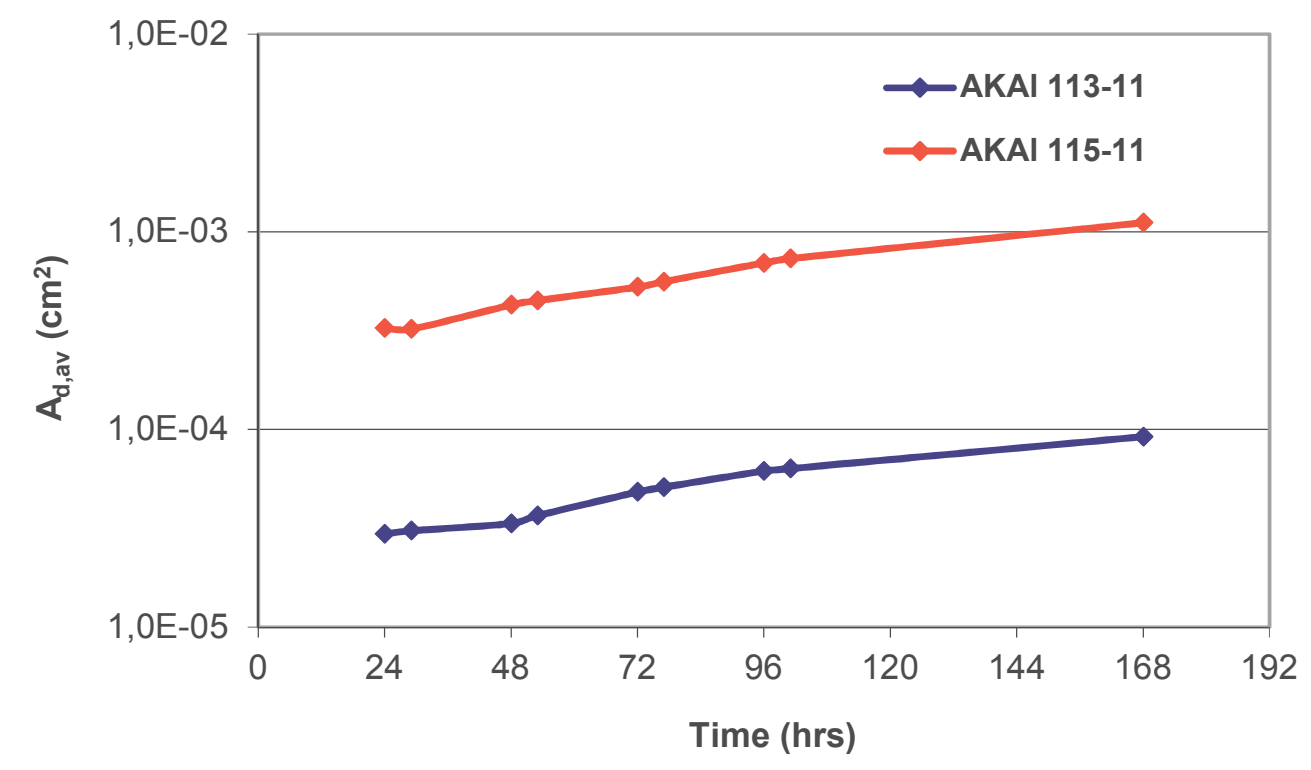

Figure 1 Time development of $A_{d, a v}$ values in 168 hrs exposure

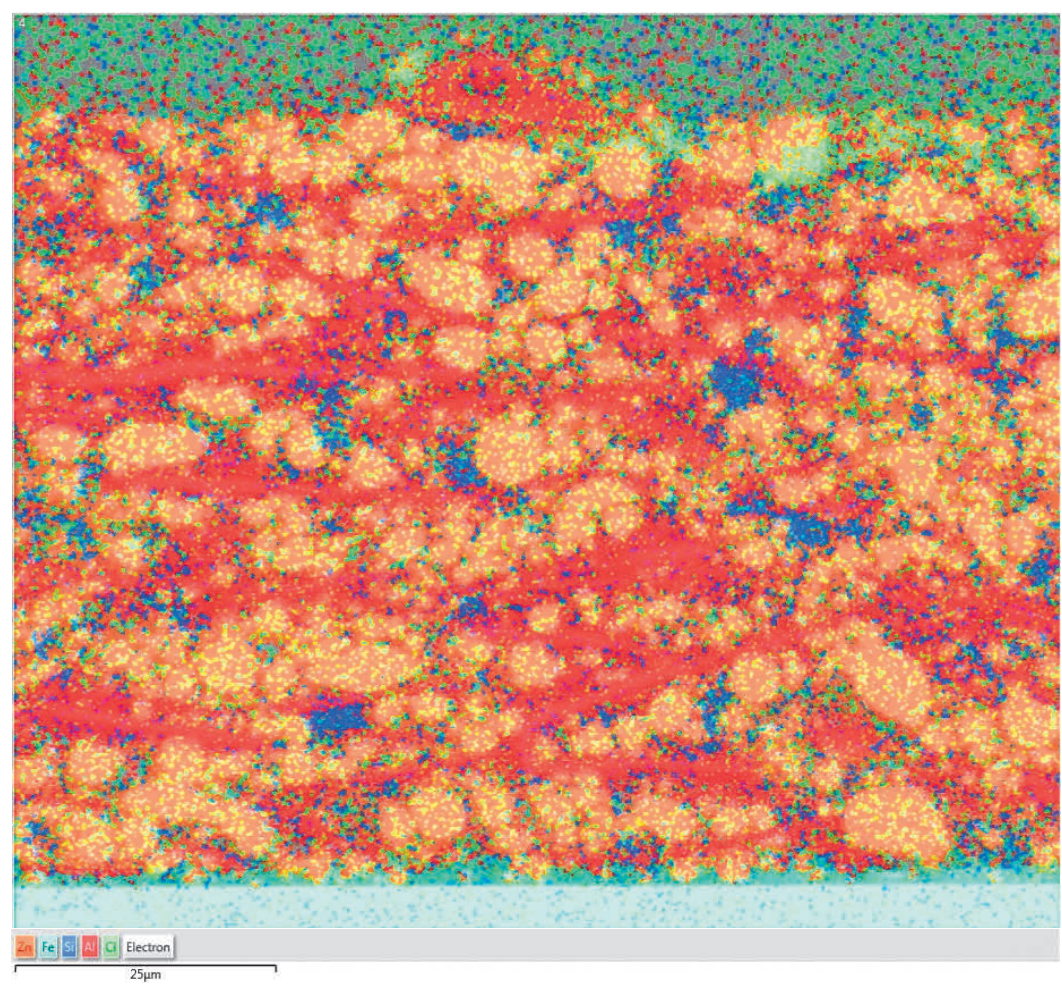

Figure 2 EDX mapping and structure (SEM-SE image) of cross-section for AKAl113 after 168 hrs exposure in $0.05 \mathrm{M} \mathrm{NaCl}$

For this type of coating formulated with somewhat higher $\wedge$ value (allowing some voids formation) the formation of new paths in the coating for $\mathrm{Cl}^{-}$ions penetration into the coating is probably easier. By this way not only water and $\mathrm{O}_{2}$ permeability but also $\mathrm{Cl}^{-}$permeability of this coating should be considered as affecting delamination kinetics of underlying steel. In spite of that still rather low $\Lambda$ value for AKAl115 seems to be able to ensure some degree of competition between disbonding conditions and conditions for formation of corrosion products with passivating effect at the metallic surface beneath the coating. 


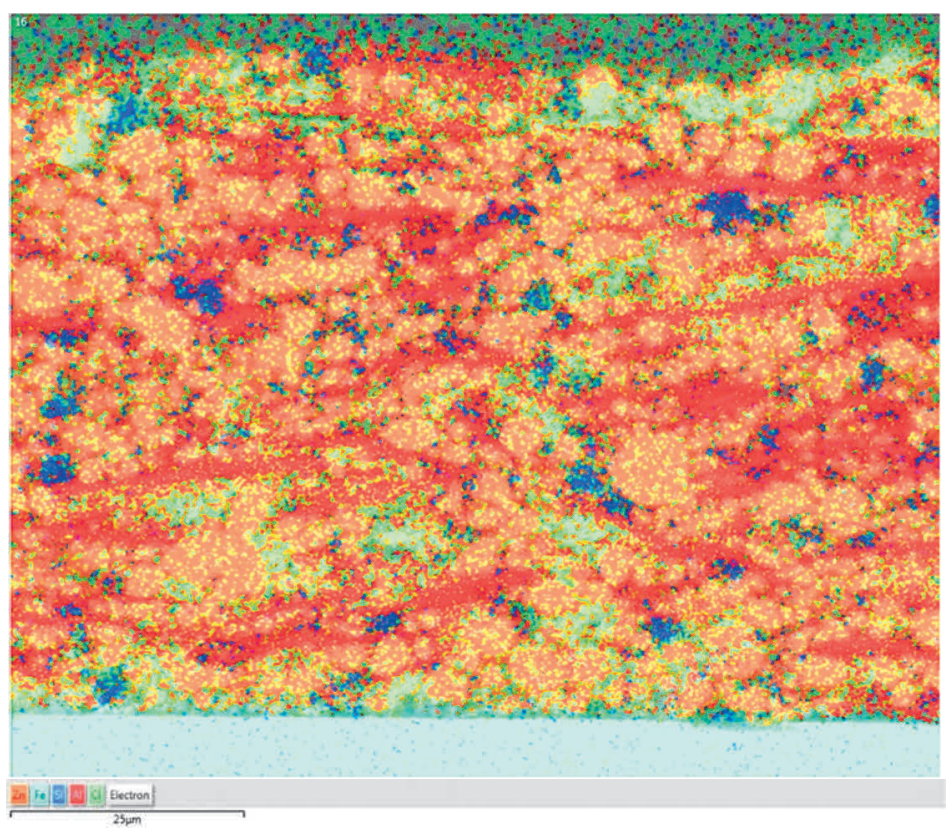

Figure 3 EDX mapping and structure (SEM-SE image) of cross-section for AKAl115 after 168 hrs exposure in $0.05 \mathrm{M} \mathrm{NaCl}$

At the same time reasonable correlation between increasing of $\Lambda$ and decreasing of barrier properties was found when MEM Noise Impedance Spectrum characteristics of tested coatings (MEM curves) estimated in the end of test were compared (Figures 4 and $\mathbf{5}$ ).

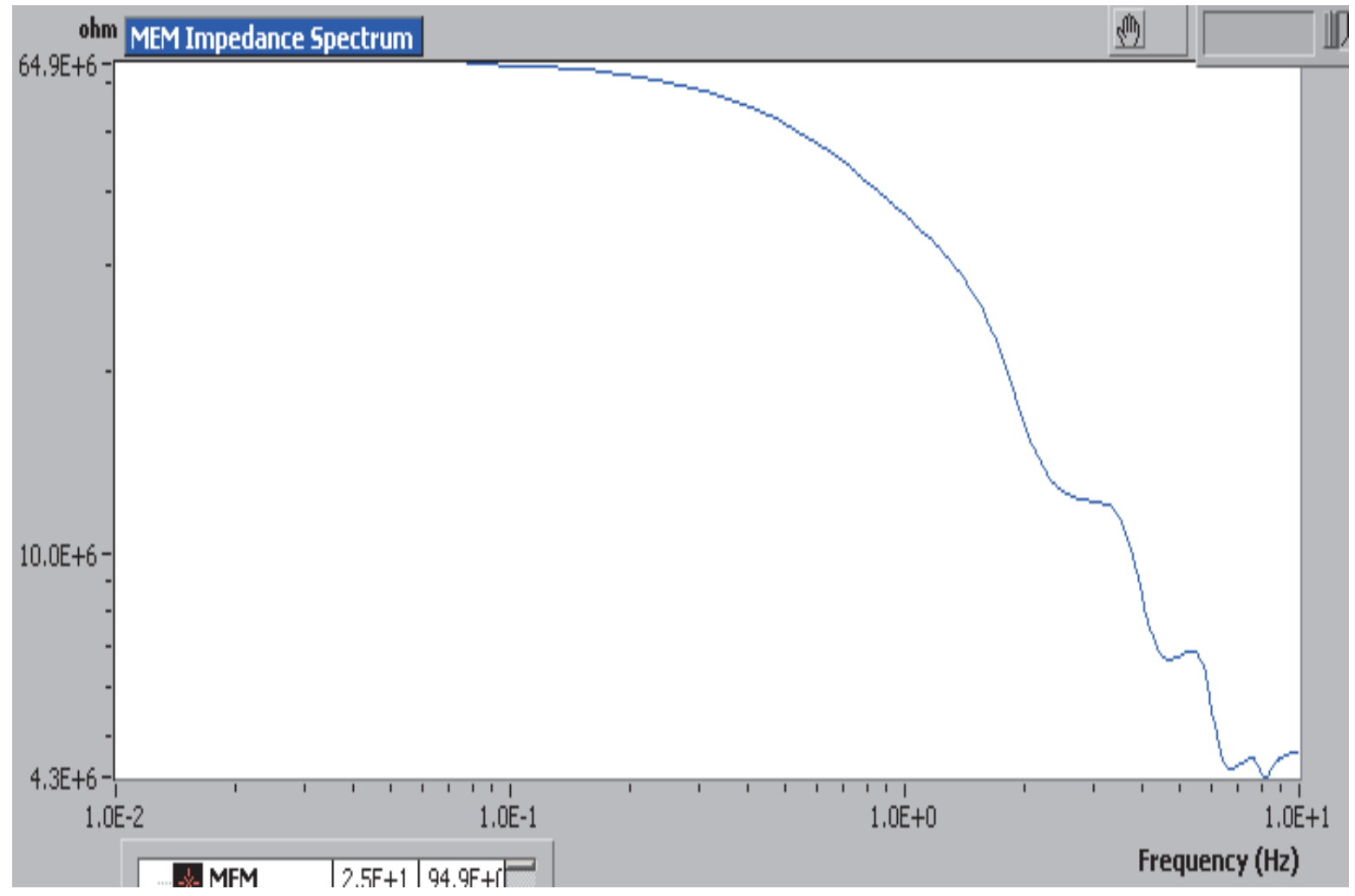

Figure 4 Noise impedance spectrum (MEM curve) for AKAl113 after 168 hrs exposure 


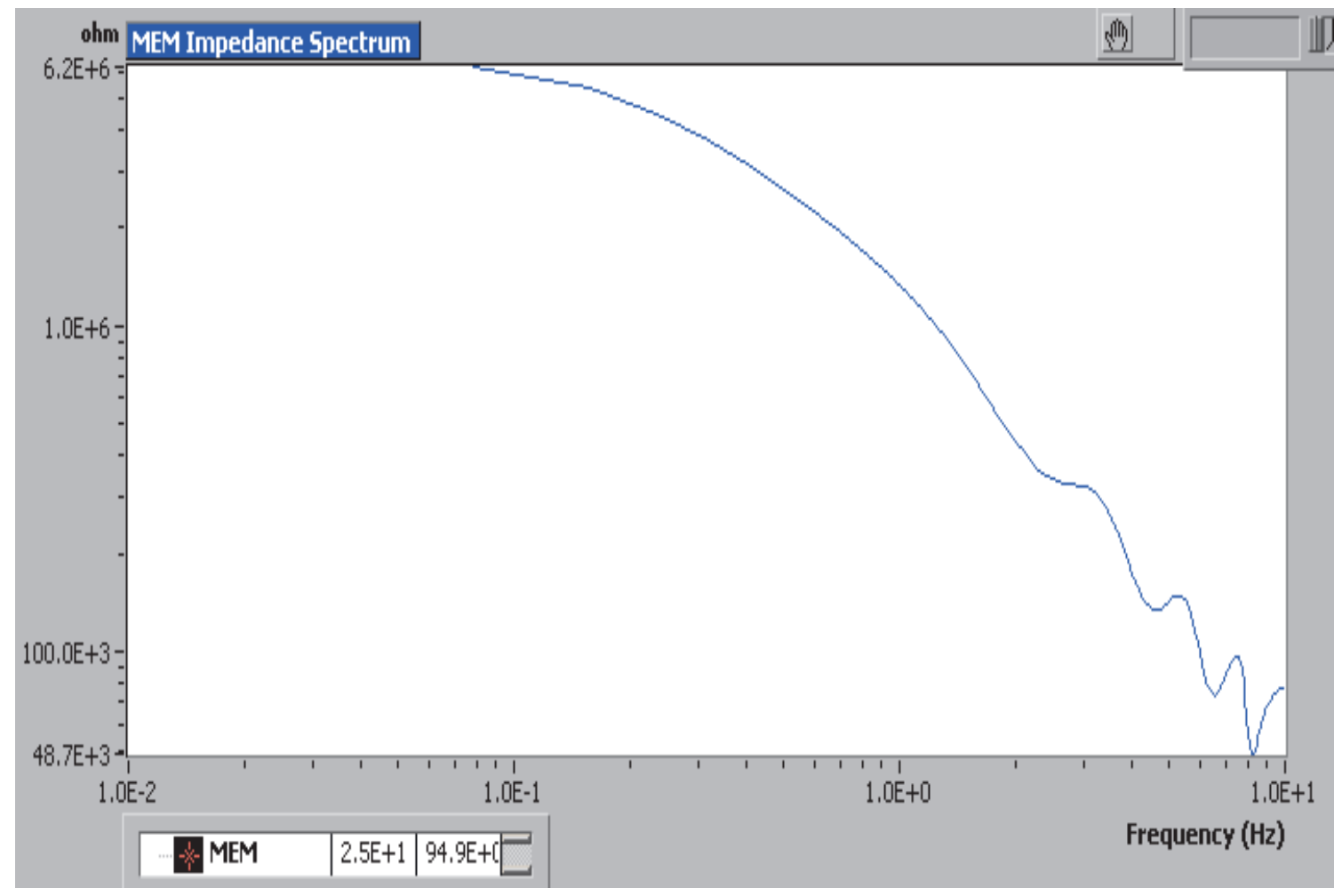

Figure 5 Noise impedance spectrum (MEM curve) for AKAl115 after 168 hrs exposure

\section{CONCLUSIONS}

The effect of possible balancing the PVC/CPVC ratio in Zn and Al pigmented epoxy coating for optimized performance of this type of coating systems has been investigated with use of ENA. In order to obtain high resistance to possible coating delamination from metallic surface value of PVC/CPVC $=0.61$ is recommended for tested coating systems.

\section{ACKNOWLEDGEMENTS}

The study was performed and paper was written with support of project MPO - IP 8/2018.

\section{REFERENCES}

[1] EREMIAS B., MINDOS L., TUREK L., HOCHMANNOVA L.: In EUROCORR 2015, Graz, Austria.

[2] SCOTT C.D.: Nature (London). 1960. vol. 188. pp. 908.

[3] LEE D.K.: J. Paint Technol. 1970. vol. 42. pp. 579.

[4] EREMIAS S., MINDOS L., TUREK L., HOCHMANNOVA L., In EUROCORR 2013, Estoril, Portugal.

[5] KENDIG M., SCULLY J. In: Corrosion. 1990. vol. 46, pp. 22.

[6] ELSNER C.I., CAVALCANTI E., FERRAZ O., Di SARLI A.R.: Progress in organic coatings. 2003. vol. 48, pp. 50.

[7] BIERWAGEN G.P., SAUNDERS T.E.: Powder Technol. 1974. vol. 10. pp. 111.

[8] BIERWAGEN G.P.: J. Paint Technol. 1972. vol. 44. pp. 46. 